\title{
WHAT MAKES A GOOD PASSENGER? FROM TEEN DRIVERS' PERSPECTIVES
}

\author{
Yi-Ching Lee ${ }^{1}$ \& Noelle LaVoie ${ }^{2}$ \\ ${ }^{1}$ Children's Hospital of Philadelphia, Philadelphia, Pennsylvania, USA \\ ${ }^{2}$ Parallel Consulting, LLC, Petaluma, California, USA \\ Email: LEEY1@email.chop.edu
}

\begin{abstract}
Summary: An exploratory study was designed to examine male and female teenage drivers' perceptions and expectations of peer passengers. Qualitative methods were used to interview and survey 16- and 17-year-old licensed drivers. 10 interviewees and 96 survey respondents were included in the analysis. Consistent with previous studies, teenage drivers were concerned about passenger-related distractions. There were noticeable differences between males and females in their perceptions of peer behaviors: females most expected passengers to be non-distracting and polite and males most expected passengers to behave maturely. Future studies should focus on social factors and the psychosocial function of driving for better understanding of the peer passenger interactions, and ultimately the development of passenger-related crash prevention efforts.
\end{abstract}

\section{INTRODUCTION}

Motor vehicle crashes are the leading cause of death for U.S. teens, accounting for more than one in three deaths in this age group, claiming the lives of about eight teenagers a day (Center for Disease Control and Prevention, 2010). In addition, more than 350,000 teens are treated each year in emergency departments for injuries resulting from a vehicle crash. One of the most significant risk factors specific to teens is driving with teen passengers (Chen, Baker, Braver, \& Li, 2000; Rice, Peek-Asa, \& Kraus, 2003; Williams, 2003). Both male and female teen drivers have increased crash risk with peer passengers present. Crash risk for teenage drivers increases exponentially with two, or three or more passengers (Chen, et al., 2000; McEvoy, Stevenson, \& Woodward, 2007). This negative effect of driving with passengers has not been found for other age groups (Engstrom, Gregersen, Granstrom, \& Nyberg, 2008).

There are gender differences in crash likelihood and risk engagement among teenage drivers and passengers. Male drivers are associated with higher rates of injury (Rice, et al., 2003) and fatal crashes (Fu \& Wilmot, 2008), and when male teen drivers transport male passengers of the same age, this combination leads to the highest fatal crash risk (Fu \& Wilmot, 2008; Ouimet et al., 2010). When a male teenage passenger is present, teens drive faster than the general traffic and allow shorter headways (Simons-Morton, et al., 2005; McKenna, et al., 1998). Male teen passengers are also less likely to speak up to a teen driver when they feel unsafe in the car, more likely to accept risk taking from other drivers, and perceive more negative consequences of addressing unsafe drivers (Ulleberg, 2004). Female teen drivers, on the other hand, are more likely than males to report being distracted by one or more of their passengers (Heck \& Carlos, 2008). 
Teens drive faster in the presence of risk-taking friends, suggesting that the social dynamics in the car afftect drivers' behaviors and decision making (Simons-Morton et al., 2011). However, to the best of our knowledge, no study has specifically explored how teenage drivers perceive peer passengers and reason about passenger behaviors. Because teenage male drivers have higher rates of fatal crashes, one would expect that their expectations and how they value peer passengers might be different from female teens. The current study was designed to explore male and female teenage drivers’ perspectives on peer passengers and their behaviors.

\section{METHOD}

Semistructured interviews and written surveys were used to explore teen drivers' perceptions and expectations of their peer passengers. The interview explored typical driver-passenger interaction, asking teens to describe:

1. Do you ever ask your passengers to do things?

2. Do you ever tell your passengers not to do things?

3. What do you think makes a good passenger?

The following items were included in the survey:

1. How do you, as a driver, interact with passengers?

2. What are you concerned about when the passenger is being annoying?

3. How do you expect your passengers to behave?

\section{Subjects}

Interview. Subjects recruited to take part in the interviews were 17 years old (4 females, 6 males) who lived in California. They all had unrestricted driver's licenses, allowing them to drive with teen passengers.

Survey. Subjects recruited to take part in the survey were 16 or 17 years old (59 females, 41 males) who lived in either California or Pennslyvania. In order to be qualified to participate in the survey, the California respondents had to have their license for no more than 24 months and the Pennsylvania respondents had to have their license for no more than 18 months. The survey was programmed by an on-line panel service company and distributed to the parents of potential respondents who are panel members of the company.

\section{Materials and Procedures}

The interviews were scheduled individually and a Ph.D. trained psychologist went to each intervewee's house or preferred location to conduct the interview. Each interview session was about an hour. The semi-structured interview consisted of 40 questions, including the subset on peer-passengers listed above, and depending on the answers, the interviewees were sometimes asked to elobarate more or provide examples for the specific instances. Questions that covered basic demographic or driving information (i.e., age, gender, licensing dates) were summarized across teens. Responses to some additional questions were fairly straightforward and could be 
easily summarized as well. For example, “ How many passengers do you drive with?” elicited consistent responses from all teens. More in-depth, descriptive questions were examined for themes. For example, responses to "What do you think makes a good passenger?" were more varied, and required researchers to categorize resposnes according to themes (e.g., respectful, not distracting).

Results from the interviews informed the design of the survey. There were 17 questions and it was estimated that the survey would be completed within 10 minutes. Once data collection was finished, the company provided de-identified data that included all the raw responses in an Excel spreadsheet to the first author. A codebook was developed by the first author and coding was completed by two trained research assistants. Categories of survey responses emerged from the actual text responses from open-ended questions. Team meetings were held to discuss the final categories of responses from open-ended questions and descriptive calculations of responses from force-choice questions as well as to resolve coding discrepencies.

\section{RESULTS}

Ten interviews were conducted and 100 respondents completed the survey. Four (3 females and 1 male) of the survey respondents had invalid data entry and were disqualified from the subsequent analysis. Here we report the qualitative results from both the interview and survey.

Interactions with passengers. The inverview participants stated that they primarily ask passengers to navigate and control music. Some example responses include:

"Navigate, text for me and give him the phone. If parents call, put on speaker phone and talk to them (turn off music); sometimes ignore phone” male driver, age 17.

"Navigating - I'm bad with directions", female driver, age 17.

These tasks seem to minimize distractions and enable the driver to concentrate on driving, suggesting that at least some teens have an understanding of how to delegate tasks to their passenger(s).

Concerns about annoying passengers. 80\% of interview participants said they would ask their passengers to be quiet if they are being too loud. 52\% of the survey respondents (half female) reported that they had asked their passengers to stop doing something annoying. Most of them said that they had to tell the annoying passengers to stop or be quiet. When the passenger is being annoying, the drivers were most concerned about being distracted (38\%) and safety/having an accident (40\%). Table 1 lists the concerns of female and male drivers and their percentages and example responses from the survey.

For females, the most reported concern was distraction and most of the respondents reasoned distraction as being not able to pay attention to driving/the traffic. For males, the most reported concern was safety, and several of them mentioned crash or accident as the potential outcome of riding with annoying passengers. 
Table 1. Categories of drivers' concerns when riding with annoying passengers

\begin{tabular}{|c|c|c|c|c|}
\hline Category & $\begin{array}{l}\text { \% of Female } \\
\text { Respondents }\end{array}$ & Example & $\begin{array}{l}\text { \% of Male } \\
\text { Respondents }\end{array}$ & Example \\
\hline Distraction & $44 \%$ & $\begin{array}{l}\text { "Being distracted from the } \\
\text { road" }\end{array}$ & $32 \%$ & $\begin{array}{l}\text { "Being distracted and } \\
\text { making a driving mistake" }\end{array}$ \\
\hline $\begin{array}{l}\text { Safety/crash/ } \\
\text { accident }\end{array}$ & $32 \%$ & "That we will be safe" & $48 \%$ & "I'm going to get a ticket" \\
\hline $\begin{array}{l}\text { Concentration/ } \\
\text { focus }\end{array}$ & $24 \%$ & $\begin{array}{l}\text { "Making too much noise } \\
\text { when I am trying to } \\
\text { concentrate" }\end{array}$ & $12 \%$ & $\begin{array}{l}\text { "That I won't be able to } \\
\text { concentrate" }\end{array}$ \\
\hline Nothing/Other & -- & -- & $8 \%$ & $\begin{array}{l}\text { "I'm usually not concerned } \\
\text { but i don't like when they } \\
\text { smoke in my car because I } \\
\text { don't smoke" }\end{array}$ \\
\hline
\end{tabular}

Expectations of passengers. Survey respondents were asked to explain how they expect their passengers to behave. Table 2 lists female and male drivers' expectations. Not suprisingly, the most reported expectation from female drivers was being quiet and not distracting. For male drivers, the most reported expectation was behaving maturely/like an adult.

Table 2. Categories of drivers' expectations of passengers

\begin{tabular}{|c|c|c|c|c|}
\hline Category & $\begin{array}{l}\text { \% of Female } \\
\text { Respondents }\end{array}$ & Example & $\begin{array}{l}\text { \% of Male } \\
\text { Respondents }\end{array}$ & Example \\
\hline $\begin{array}{l}\text { Quiet/ } \\
\text { Not distracting }\end{array}$ & $42.9 \%$ & $\begin{array}{l}\text { "Quiet enough that they're } \\
\text { not hazardous to my } \\
\text { driving” }\end{array}$ & $14.3 \%$ & "Not to distract me" \\
\hline $\begin{array}{l}\text { Polite/ } \\
\text { respectful }\end{array}$ & $26.8 \%$ & $\begin{array}{l}\text { "I expect my passengers to } \\
\text { have respect for me while I } \\
\text { am behind the wheel and to } \\
\text { act appropriately" }\end{array}$ & $12.5 \%$ & $\begin{array}{l}\text { "I expect them to be } \\
\text { respectful and not do } \\
\text { anything stupid or illegal" }\end{array}$ \\
\hline Sit still & $14.3 \%$ & $\begin{array}{l}\text { "Just sit and chill. sing a bit } \\
\text { to the radio" }\end{array}$ & $8.9 \%$ & $\begin{array}{l}\text { "Sit stll - quiet } \\
\text { conversation - no throwing } \\
\text { stuff or jumping around" }\end{array}$ \\
\hline $\begin{array}{l}\text { Mature/ } \\
\text { adult-like }\end{array}$ & $12.5 \%$ & $\begin{array}{l}\text { "Just be normal and dont } \\
\text { do dumb stuff like throw } \\
\text { stuff out the windows" }\end{array}$ & $30.4 \%$ & $\begin{array}{l}\text { "Like they were in their } \\
\text { parents car" }\end{array}$ \\
\hline Helpful & $1.8 \%$ & "Be helpful” & $3.6 \%$ & "Helpful" \\
\hline Fun & $1.8 \%$ & $\begin{array}{l}\text { "I want my passengers to } \\
\text { have fun" }\end{array}$ & $1.8 \%$ & "Have fun" \\
\hline
\end{tabular}

When interview participants were asked “What do you think makes a good passenger?,” they stressed that good passengers are not distracting, help keep the driver awake, and bring potential threats to the driver's attention. Example responses include:

"Sometimes it's ok to backseat drive, if it's a close call it's ok to tell them to slow down." female driver, age 17.

"Best type of passenger is as focused on road as you are, knows what's distracting and doesn’t do it.” male driver, age 17. 
Because some of our interviewees mentioned back seat driving, we asked survey respondents to differentiate between a passenger who acts like a backseat driver and one who is being helpful. Table 3 lists the characteristics of a backseat driver, by female and male respondents. One characteristic of a backseat driver that stood out among male respondents was demanding/controling of the car. Females more evenly considered annoying, demanding/controling, and critical/stressful as characteristics of a backseat driver. Another difference that is of interest was that males three times more than females thought helpful driver and backseat driver were not different.

Table 3. Characteristics of a backseat driver

\begin{tabular}{|c|c|c|c|c|}
\hline Category & $\begin{array}{l}\text { \% of Female } \\
\text { Respondents }\end{array}$ & Example & $\begin{array}{l}\text { \% of Male } \\
\text { Respondents }\end{array}$ & Example \\
\hline Annoying & $23.2 \%$ & $\begin{array}{l}\text { "Backseat drivers are } \\
\text { extremely annoying" }\end{array}$ & $12.5 \%$ & "One is annoying" \\
\hline $\begin{array}{l}\text { Demanding/ } \\
\text { controlling }\end{array}$ & $19.6 \%$ & $\begin{array}{l}\text { "A backseat driver just } \\
\text { directs me and tells me } \\
\text { what to do" }\end{array}$ & $30 \%$ & $\begin{array}{l}\text { "A backseat driver is } \\
\text { always telling you want to } \\
\text { do or yelling out" }\end{array}$ \\
\hline $\begin{array}{l}\text { Critical/ } \\
\text { stressful }\end{array}$ & $19.6 \%$ & $\begin{array}{l}\text { "A backseat driver would } \\
\text { pick out every bad little } \\
\text { mistake forcefully" }\end{array}$ & $7.5 \%$ & $\begin{array}{l}\text { "One who is being a } \\
\text { backseat driver ridicules } \\
\text { you as you drive" }\end{array}$ \\
\hline Not helpful & $14.3 \%$ & $\begin{array}{l}\text { "Don’t tell me helpful } \\
\text { things” }\end{array}$ & $15 \%$ & "Not being helpful” \\
\hline Tone & $7.1 \%$ & "The tone in their voice" & $7.5 \%$ & "The tone of voice" \\
\hline I don’t know & $10.7 \%$ & "I don’t know" & $10 \%$ & “I don’t know" \\
\hline No difference & $5.4 \%$ & "Not much" & $17.5 \%$ & $\begin{array}{l}\text { "Nothing-- they should } \\
\text { both leave me alone" }\end{array}$ \\
\hline
\end{tabular}

$81 \%$ of survey respondents (42 females, 36 males) believed that passengers who drive regularly are more respectful and helpful than passengers who don’t drive yet.

\section{DISCUSSION}

This explorotary study was intended to understand how male and female teenage drivers perceive peer passengers and reason about their behaviors. In the literature, male drivers are associated with higher crash likelihood compared to females; therefore, we expected to see some gender-based differences in teenage drivers’ perceptions and expectations.

Consistent with previous findings (Ginsburg et al., 2008; Heck \& Carlos, 2008), teenage drivers were concerned about and disliked distraction and loud talking. Distraction was mentioned by many participants in the context of potential negative outcomes of having passengers and especially when passengers were being annoying. It was associated with talking too loudly and needing passengers to be quiet. The responses from the teen participants also suggest that at least some of them have an understanding of safety consequences of interacting with passengers. They are aware that passengers can impair their driving and their ability to pay attention to the road. Some also know to delegate non-driving tasks to their passengers.

All of the teen participants had some similar concerns about passengers being annoying. Their concerns fell within the categories of distraction, safety, and concentration. However, the specifics of what it means to be annoying varied by gender. Males and females seemed to have 
described their expectations of peer passengers differently. The two most reported categories of expectations from female drivers were quiet/not distracting and polite/respectful. Their responses seemed to speak to the importance of having clear rules for how to behave in the car. The most reported category of expectation from male drivers was mature/adult-like, and the responses were relatively less concrete and made references to adults or parents. When asked to differentiate between a helpful driver and a backseat driver, both genders mentioned passengers who are directing/controlling as charactieristics of backseat drivers. Females also mentioned passengers who were annoying and being critical as the characteristics of backseat drivers.

It is possible that males and females use different terms to describe similar expectations. It is also possible that males and females value the function of driving differently. Some may believe the driver and the passenger share the same goal or interest and choose to drive together as a winwin situation. As a result, they need to have clearly defined roles and show respect for each other. Others may believe the driver and the passenger have competing motives (e.g., showing off and sensation seeking) for driving together and as a result become critical of each other's behaviors.

In conclusion, findings from the current study suggest that there might be socio-cultural factors influencing male and female teenage drivers' perceptions of peer passengers. There seems to be different labeling and descriptions of expectations that are different between genders. Future studies should examine interactions between same-gender and mixed-gender pairs and the psychosocial function of driving, as this qualitative look at teens' perceptions of passengers suggests that gender differences and the nature of relationships would be interesting areas of research for developing a better understanding of peer passenger interactions, and ultimately the detrimental effects of peer passengers on crash rates.

These data were collected to provide an initial look into teen drivers' perspectives on peer passengers and their behaviors. Participant sampling was based on convenience, as such this study was not designed to provide population-based estimates of the relative frequencies or to make comparisons among demographic subgroups.

\section{ACKNOWLEDGMENT}

The authors would like to thank Dana Bonfiglio, Catherine Smith, and Michael Chang for their administrative support during this project. This material is based upon work supported by the National Science Foundation under Grant No. IIP-1110201. Any opinions, findings, and conclusions or recommendations expressed in this material are those of the authors and do not necessarily reflect the views of the National Science Foundation.

\section{REFERENCES}

Centers for Disease Control and Prevention. (2010). Web-based Injury Statistics Query and Reporting System (WISQARS). National Center for Injury Prevention and Control, Centers for Disease Control and Prevention. 
Chen, L. H., Baker, S. P., Braver, E. R., \& Li, G. H. (2000). Carrying passengers as a risk factor for crashes fatal to 16-and 17-year-old drivers. Jama-Journal of the American Medical Association, 283(12), 1578-1582. doi: 10.1001/jama.283.12.1578

Engstrom, I., Gregersen, N. P., Granstrom, K., \& Nyberg, A. (2008). Young drivers - Reduced crash risk with passengers in the vehicle. Accident Analysis and Prevention, 40(1), 341-348. doi: 10.1016/j.aap.2007.07.001

Fu, H., \& Wilmot, C. G. (2008). Effect of Passenger Age and Gender on Fatal Crash Risks of Young Drivers. Transportation Research Record(2078), 33-40. doi: 10.3141/2078-05

Ginsburg, K. R., Winston, F. K., Senserrick, T. M., Garcia-Espana, F., Kinsman, S., Quistberg, A., . . Elliott, M. R. (2008). National young-driver survey: Teen perspective and experience with factors that affect driving safety. Pediatrics, 121(5), E1391-E1403. doi: 10.1542/peds.2007-2595

Heck, K. E., \& Carlos, R. M. (2008). Passenger distractions among adolescent drivers. Journal of Safety Research, 39(4), 437-443. doi: 10.1016/j.jsr.2008.03.003

McEvoy, S. P., Stevenson, M. R., \& Woodward, M. (2007). The contribution of passengers versus mobile phone use to motor vehicle crashes resulting in hospital attendance by the driver. Accident Analysis and Prevention, 39(6), 1170-1176. doi: 10.1016/j.aap.2007.03.004

Ouimet, M. C., Simons-Morton, B. G., Zador, P. L., Lerner, N. D., Freedman, M., Duncan, G. D., \& Wang, J. (2010). Using the US National Household Travel Survey to estimate the impact of passenger characteristics on young drivers' relative risk of fatal crash involvement. Accident Analysis and Prevention, 42(2), 689-694. doi: 10.1016/j.aap.2009.10.017

Rice, T. M., Peek-Asa, C., \& Kraus, J. F. (2003). Nighttime driving, passenger transport, and injury crash rates of young drivers. Injury Prevention, 9(3), 245-250. doi: 10.1136/ip.9.3.245

Simons-Morton, B. G., Ouimet, M. C., Zhang, Z. W., Klauer, S. E., Lee, S. E., Wang, J., .. . Dingus, T. A. (2011). The Effect of Passengers and Risk-Taking Friends on Risky Driving and Crashes/Near Crashes Among Novice Teenagers. Journal of Adolescent Health, 49(6), 587-593. doi: 10.1016/j.jadohealth.2011.02.009

Ulleberg, P. (2004). Social influence from the back-seat: factors related to adolescent passengers' willingness to address unsafe drivers. Transportation Research Part F-Traffic Psychology and Behaviour, 7(1), 17-30. doi: 10.1016/j.trf.2003.09.004

Williams, A. F. (2003). Teenage drivers: patterns of risk. Journal of Safety Research, 34(1), 515. doi: Pii s0022-4375(02)00075-0 